[JSRNC 13.4 (2019) 409-413]

JSRNC (print) ISSN 1749-4907

http://doi.org/10.1558/jsrnc.40382

JSRNC (online) ISSN 1749-4915

\title{
Special Issue Introduction: \\ Popular Culture, Religion, and the Anthropocene
}

\author{
Guest Editors: Lisa H. Sideris and John Whalen-Bridge \\ Lisa H. Sideris \\ Department of Religious Studies \\ Center for Religion and the Human \\ Indiana University \\ Bloomington, IN 47401, USA \\ lsideris@indiana.edu \\ John Whalen-Bridge \\ English Language and Literature \\ National University of Singapore \\ Singapore 119260 \\ jwb@nus.edu.sg
}

Create a 'Google Alert' for the word Anthropocene and wait for your email inbox to be flooded. You quickly get a sense of how widely the term has been adopted in the broader culture and the (often uncritical) variety of ways it is being invoked and interpreted. The Anthropocene is the focus of a steady stream of scientific papers, humanities scholarship, blogs, small-town newspaper articles, and letters to the editor, and it features prominently in a range of artistic productions, museum exhibitions, and feature films. The Anthropocene is invoked in tones both of dire warning and hushed veneration, and virtually everything in between. Perhaps the term's center of gravity has to do with the increasingly worrying phenomenon of catastrophic climate change. In 2016, in response to such concerns and to the gap between what governments can and should do, a group of scholars assembled at the National University of Singapore to explore interrelations between religion and 
the Anthropocene, as refracted through the prism of popular culture. ${ }^{1}$ This forum represents some of the fruits of that conversation.

As Bron Taylor discusses in the opening essay, the claim that humans have entered a new geological epoch in which our own species has decisively (if not exactly intentionally) altered the earth system continues to engender debate and controversy. Many scientists currently throw support behind a mid-twentieth-century start date for the Anthropocene, a period often referred to as the 'Great Acceleration', when intensified human activity - population growth, energy consumption, telecommunications, transportation, deforestation, pollution, and water use, among other indicators-began perceptibly to shift the state and functioning of the Earth system. Others (including Taylor) disagree, arguing that human alteration of the planet can be traced as far back as the Late Pleistocene. Humans (or hominids), on this account, have long refashioned ecosystems, domesticated plants and animals, and driven other species to extinction. Trends culminating in the Industrial Revolution and, more recently, the Great Acceleration seem to have been underway for thousands or tens of thousands of years.

While scholars have articulated many good reasons to critique and resist the term (see Crist 2013; Malm and Hornborg 2014) the Anthropocene train appears to have left the station, for better or for worse. However these debates might be resolved, it is clear that the idea of a new geological age marked by human alteration of the planet-an epoch named, auspiciously or inauspiciously, after our own species-has fired the popular imagination. But is there something religious about these developments? Grand narratives of human evolution and sweeping claims of humanity's place within nature and the cosmos often function in ways that are implicitly, if not explicitly, religious and mythic (Sideris 2016, 2017). The Anthropocene is no exception. Anthropocene discourse resonates with declensionist and ascendant cosmogonies, tales of hubris and forbidden knowledge. It taps into millenarian hopes and fears, and draws from ancient reservoirs of prophecy, theodicy, and eschatology. Whether the narrative plot hints at grave human error, punishment, and imminent apocalypse, or exalts humans' heroic and exceptional worldmaking capacities, the stories we tell about our present crisis stake a claim to the kind of creature 'we' are. They encourage particular visions of the past and (especially) the future, while closing down other possible avenues for imaging the human and the human-nature relationship.

1. This workshop was funded by Singapore's Ministry of Education grant R 103-000-116-112.

(C) Equinox Publishing Ltd 2020.

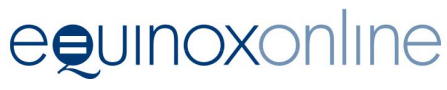


Popular culture, then-defined broadly in this forum to include vacation theme parks, natural history museums, art exhibitions, documentary films, and viral internet-driven images, among other cultural productions-is a repository of the various religious and religion-resembling ways in which humans are interpreting, and transmitting to others the claim that our species is radically remaking the planet. The intensified entanglement of humans and nature, the collapse of culture/nature binaries that is taken by some to signify the Anthropocene's arrival, might be welcomed as a positive development, dislodging humans from their position external to, or hovering transcendently above, a reified entity called 'nature' or 'the wild'. Nature understood in traditional terms - a place whose value depends upon the absence of humans and their activities - has arguably figured prominently in imperialist, expansionist, racist, and romantic discourses on the environment (Cronon 1996). For some, the Anthropocene imaginary yields visions of a planet Earth that is more powerful, more alive than ever-defiant, even, in its refractory response to our species' destructive omnipresence (Hamilton 2017). Anthropocene agencies abound and proliferate. Gaia will have her revenge. All the same, according to some narratives (and even, at times, the same narratives), a special niche remains for the equally powerful, infinitely adaptable human creature who survives, and even thrives, by transforming environments and coopting evolutionary processes to achieve its own ends. On this account, the Anthropocene and associated 'challenges' like climate change serve to mobilize and hone our uniquely human forms of ingenuity, our species-specific penchant for pluck.

After orienting readers to the three central concepts of this forumpopular culture, religion, and the Anthropocene-Bron Taylor's essay takes up the question of Disney's ambiguous environmental and colonial legacy, inquiring into the ways in which these three concepts 'have been contested, entangled, and changed, in Disney's Worlds'. If Disney-the man, the theme parks, and various Disney productions-were historically invested in expressions of civil religion that fueled frontier expansionism, American exceptionalism, techno-optimism, and the attendant subordination of Native peoples and untamed lands to an advancing white and Christian civilization, Taylor discerns a kinder, gentler Disney emerging over recent decades. The civil religion and nationalist 'we feeling' of Disney's earlier days has partially given way to, or perhaps reinvented itself as, an Anthropocene-resistant strain of dark green spirituality (Taylor 2010). Today's patrons of Disney productions encounter films, documentaries, and theme park exhibitions that showcase values of biodiversity and human kinship with all life, exhorting us to connect emotionally, even spiritually, with nature and its 
increasingly imperiled wonders. A new and potentially subversive kind of 'we' and 'place' feeling is palpable in Disney's 'religion-resembling call to a ritualized and sensory experience of nature' and its reminders that 'we are one in relation' and 'one with the oceans'.

Reminders that we-or at least we humans—are 'all one' are issued repeatedly at the Smithsonian National Museum of Natural History. In her essay, Lisa Sideris takes a tour of the controversial David H. Koch Hall of Human Origins, where religious-like appeals to human unity and exceptionalism are plentiful. She pauses to analyze the evolutionary/ Anthropocene narrative proffered by the Hall of Human Origins, noting the various ways in which it conveniently dovetails with a certain Kochlike mode of 'insouciance' regarding the impacts of climate change. She discerns the outlines of a deep-time narrative that treats climate fluctuation as a constant and not unwelcome feature of the planet's long history, and a driving force of human intelligence, creativity, and evolutionary success. Pulling back the curtain to reveal the exhibition's, and its architects', lesser-known sources and forms of religiosity, Sideris argues that the Smithsonian's account of what it means to be human valorizes and naturalizes destructive domination of the planet, presenting climate change and associated harms as merely the latest interesting challenge to be dispatched by our 'big-brained' species.

Sideris's somewhat informal, first-person reading of a popular science exhibit and its problematic rendering of the Anthropocene is followed by Adrian Ivakhiv's much more systematic theorization of the connections between images (of many sorts), religion, and the Anthropocene. Adopting a process-semiotic approach that treats images as sensorially perceptible forms that mediate relationships between humans and the world around us, Ivakhiv argues that an 'ecology of images' is already at large, and built into, the world around us; our task is 'to better understand how these ecologies have worked in the past and how they are working today' so that we might exist more ethically within them. Ivakhiv presents a careful typology of image-relations, describing in ideal terms how understandings of images relate to understandings of reality, and noting the links between image regimes and religious, spiritual, and cultural practices. The Anthropocene has seen the proliferation of certain types of image regimes over others. Ivakhiv asks: What forms of image production are most 'promising' for addressing our Anthropocene predicament? To think through these and other ecocritical questions, he turns to a popular multi-media project on the Anthropocene and offers a preliminary but insightful assessment.

Ivakhiv's treatment of the relationship between understandings of images and reality is useful for analyzing the forms of documentary 
storytelling-or 'world-making' — discussed in Luis Vivanco's essay. Even the most secular-seeming and ostensibly reality-based nature documentaries and wildlife films, Vivanco argues, draw deeply from 'symbolic wellsprings and archetypal, even mythological, narrative forms' in their practices of world-making. What happens when these storylines begin to shift away from nature presented as an orderly, balanced, autonomous, or Edenic system, toward nature understood in chaotic Anthropocenic terms, where every aspect of nature is shaped by, and dependent upon, human decisions and activities? Are nature films 'reliable vehicles' for depicting current realities-the slow burn of the environmental crisis and the increasingly complex and entangled relationships between humans and wildlife? This new genre of Anthropocenic 'creation tales' runs the gamut, from upbeat stories of 'ingenious' conservation solutions to alarming visual projections of an unfolding planet-wide apocalypse. As with Ivakhiv's analysis of image regimes that speak to our Anthropocene predicament, Vivanco's work underscores that 'creating wildlife tales at the threshold of the Anthropocene requires the production of new visual symbolism, moral imaginaries, and etiologies for a planetary future'.

The essays in this forum offer just a sampling of the ways in which the Anthropocene and its mythopoeic and cosmogonic resonances are seeping into popular culture. Taken together, they encourage us to attend more closely to the Anthropocenic images, symbols, and stories that are saturating and reshaping our worlds and, perhaps, to inquire more deeply into who is crafting these productions, and to what ends.

\section{References}

Crist, Eileen. 2013. 'On the Poverty of Our Nomenclature', Environmental Humanities 3: 129-47. Doi: https:/ / doi.org/10.1215/22011919-3611266.

Cronon, William. 1996. 'The Trouble with Wilderness: Or, Getting Back to the Wrong Nature', Environmental History 1.1: 7-28. Doi: https://doi.org/10.2307/3985059.

Hamilton, Clive. 2017. Defiant Earth: The Fate of Humans in the Anthropocene (Cambridge: Polity Press).

Malm, Andreas, and Alf Hornborg. 2014. 'A Geology of Mankind? A Critique of the Anthropocene Narrative', The Anthropocene Review 1.1: 62-69. Doi: https://doi. org $/ 10.1177 / 2053019613516291$.

Sideris, Lisa. 2016. 'Anthropocene Convergences: A Report from the Field', in Robert Emmett and Thomas Lekan (eds.), 'Whose Anthropocene? Revisiting Dipesh Chakrabarty's "Four Theses"', RCC Perspectives: Transformations in Environment and Society 2: 89-96.

-2017. Consecrating Science: Wonder, Knowledge, and the Natural World (Oakland, CA: University of California Press).

Taylor, Bron. 2010. Dark Green Religion: Nature Spirituality and the Planetary Future (Berkeley: University of California Press). 